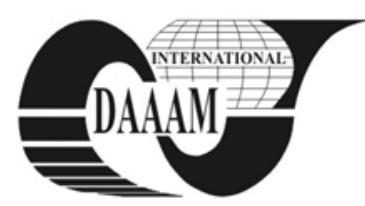

Annals of DAAAM for 2011 \& Proceedings of the 22nd International DAAAM Symposium, Volume 22, No. 1, ISSN 1726-9679 ISBN 978-3-901509-83-4, Editor B. Katalinic, Published by DAAAM International, Vienna, Austria, EU, 2011 Make Harmony between Technology and Nature, and Your Mind will Fly Free as a Bird Annals \& Proceedings of DAAAM International 2011

\title{
ON THE CONTROLLING OF THE COILERS FROM A METAL EXTRUSION PRESS
}

\author{
CIUPITU, L[iviu]; BROTAC, S[orin] \& IVANESCU, N[ick] A[ndrei]
}

\begin{abstract}
Present article is focusing to the control of the coiler devices of an extrusion press of 2500 tons-force used in order to obtain coiled wires of brass and copper. The driving of coiler devices is done by another hydraulic system than the main hydraulic system of extrusion machine, with 2 rotary hydraulic motors for each coiling unit. Maintain the synchronization between the speed of press's ram during the pressing and the rotation of coilers during the coiling, in case of hydraulic driving, is a difficult task and the main goal of present paper.

Key words: SCADA system, extrusion press, brass and copper, coiler, hydraulic drive
\end{abstract}

\section{INTRODUCTION}

The process of extrusion, in the case of ACB extrusion press (***- Loire, 1976) of 2500 tons-force (arround 24.5 MN) used for metal of brass and copper, is an usual direct extrusion process as following: stock material (the blank, also called "billet"), in the form of dollops of $220 \mathrm{~mm}$ diameter and the lenght of $250-750 \mathrm{~mm}$, is continuously fed to heating chambers and carried along by a feed-device within (Fig. 1). The feeddevice is driven via hydraulic drive system and tight speed and force control is critical to product quality. As it is conveyed into heating chambers the round blank piece is heated above the material's re-crystallization temperature (between 600 and 1100 Celsius degree in case of brass and copper) to keep the material from work hardening and to make it easier to be pushed through the die. The heated blank piece is then loaded into the container in the press, compressed, and forced out of the container chamber at a steady rate through a die. The extrusion ratio is defined as the starting cross-sectional area (the container chamber cross-sectional area) divided by the crosssectional area of the final extrusion (i.e. the area of the holes in the die). The immediate cooling results in resolidification of heated metal into a continually drawn piece whose cross section matches the die pattern. This die has been engineered and machined to ensure that the material flows in a precise desired shape. Afterward the extrusion is stretched in order to straighten it. There are downstream processing equipments that are fed by the extruder. Depending on the end product, the extrusion may be blown into film, wound, spun, folded, and rolled, plus a number of other possibilities.

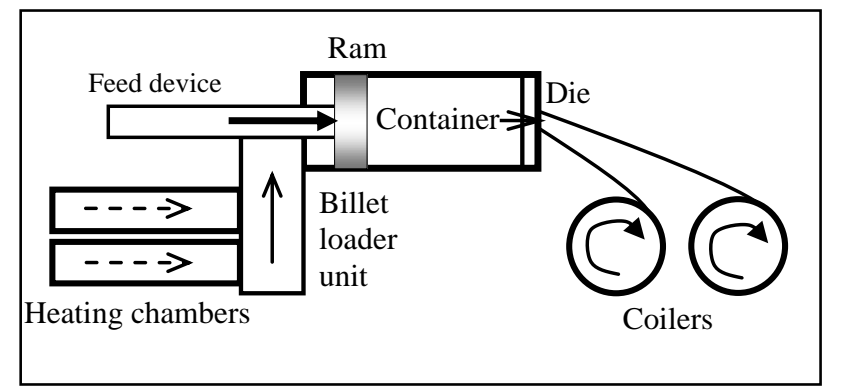

Fig. 1. Extrusion press scheme

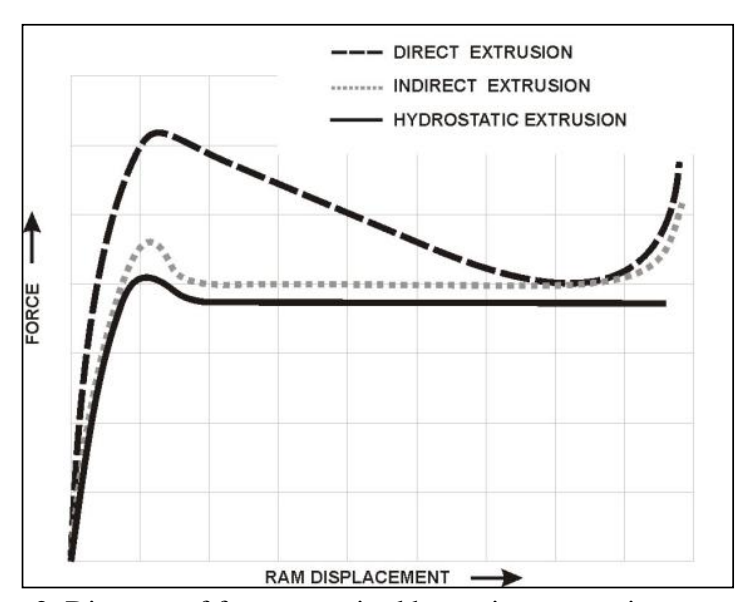

Fig. 2. Diagram of forces required by various extrusion types

In Fig. 2, a diagram with variation of ram force with respect to the displacement of ram during the pressing process is ploted. In case of direct extrusion (dashed line) the flow of the metal is parallel to the active force. As is seen there is a quasilinear variation of force during the extrusion from the beginning of pressing until the end of the process. In case of indirect extrusion (doted line) the draining of the metal is contrary to the direction of the applied force, and force is constant during the pressing. In case of hidrostatic extrusion (Inoue. \& Nishihara, 1985) the force remains constant even at the end of pressing (Fig. 2 - solid line).

Hydraulic driving is used in order to obtain very high forces needed to make the material to be deformed in plastic domain. In the case of wires the deformation ratio is very big because of small holes from the die (diameter $d=6$ to $25 \mathrm{~mm}$ ). So very high forces, arround 2500 tons-force, are necessary. But, as is very well known, the controling of hydraulic units is difficult even in the case of machines where the forces are not so big (Guo et.al., 1994). In our case, more of that, 2 independent hydraulic units must to be controlled in order to obtain a sincronicity of movements. More of that, in case of wires coiled in coils, the diameter of the coil of wire is increasing during the coiling and the rotation speed of coiler must to be controled in acord to the speed of feeding device, speed which is not constant but it depends to the plasticity of material.

\section{COILING UNITS}

Present article is focusing to the the control of the coiler devices of extrusion machine, used in order to obtain rolled coils of wires. The driving of coiler devices is done by an hydraulic system with 2 rotary hydraulic motors for each unit. Mentaing of sincronicity between the speed of feed-device and the rotation of coilers, in case of hydraulic driving, is a difficult task and the main goal of present paper.

A detail from hydraulic scheme of coiler with the rotary hidraulic motor is presented in Fig. 3. 


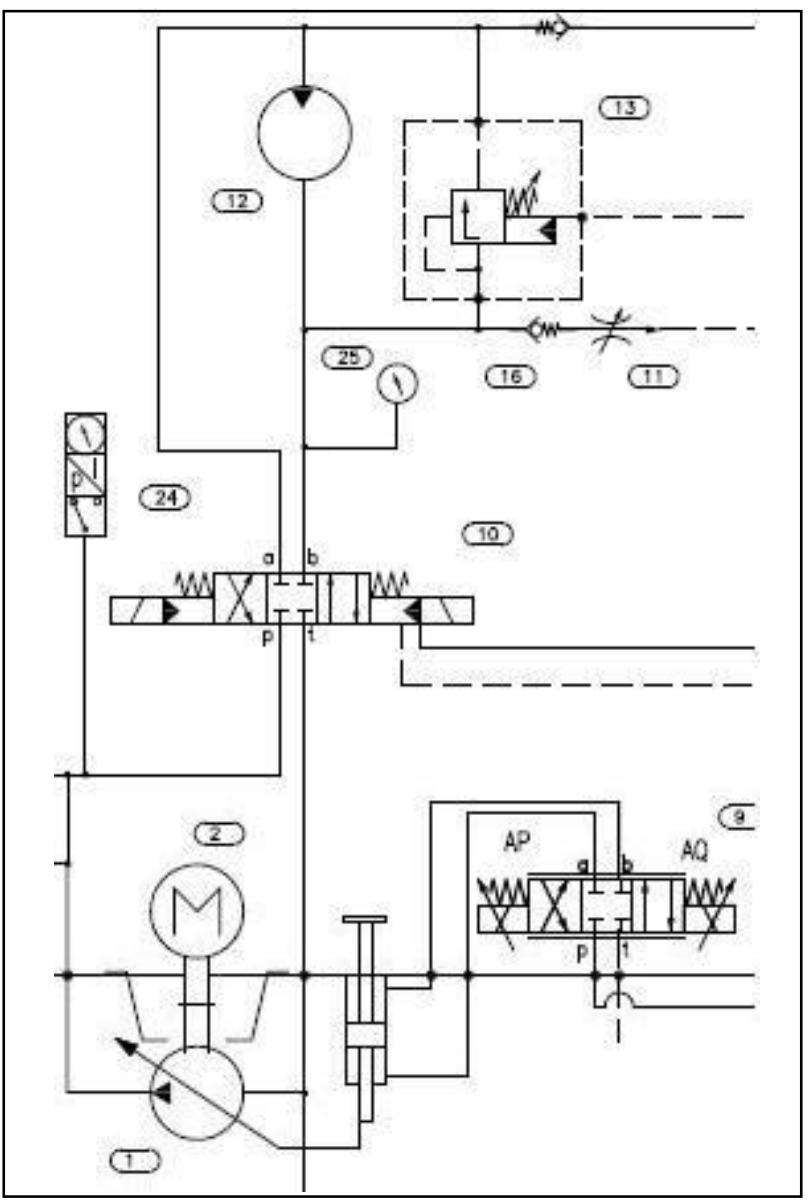

Fig. 3. Hydraulic scheme of coilers (rotary motor detail)

The variable rotation speed of coiler's hydraulic rotary motor, denoted by 12 in Fig. 3, is obtained by using a variable displacement pump denoted by 1 . The axial piston pump 1 has an adjustable swashplate which is modifying the displacement, mechanism which is actuated by an hydraulic piston from a pilotage hydraulic circuit. The linear moving of piston is controled by using the electro-valve denoted by 9 in Fig. 3 . Comands denoted by AP and AQ for each solenoid of electrovalve type 4WRA10 come from the pump command card (*** Bosh-Rexroth, 2010) and determine the moving of axial piston pump's swashplate by a simple linkage (a connecting rod).

\section{COMMAND AND CONTROL}

The command to the amplifier card of pump is prepared in a PLC (*** - Honeywell, 2010) according to the speed of ram. The real speed of ram is taken from a linear transducer through an input analogique card at 14 bits. The relation between the angular speed of coiler and the speed of ram during the pressing is:

$$
\omega_{\text {ref }}=k \frac{v_{\text {ram }}}{R}
$$

where:

$k$ - is the extrusion ratio (up to 722 );

$R$ - is the radius of coiler (from $0.55 \mathrm{~m}$ up to $1.25 \mathrm{~m}$ ).

This value is scaled to 14 bits, compared with the real value of coiler angular speed and transfered to the pump command card through a PID algorithm regulator. The value of real type from an analogique output card of PLC is interpreted an amplified in pump command card which is preparing the signals for proportional valve solenoids. The command circuit is closing by the correction of angular speed of coiler.

As for the control circuit on the feed-back way, a simple

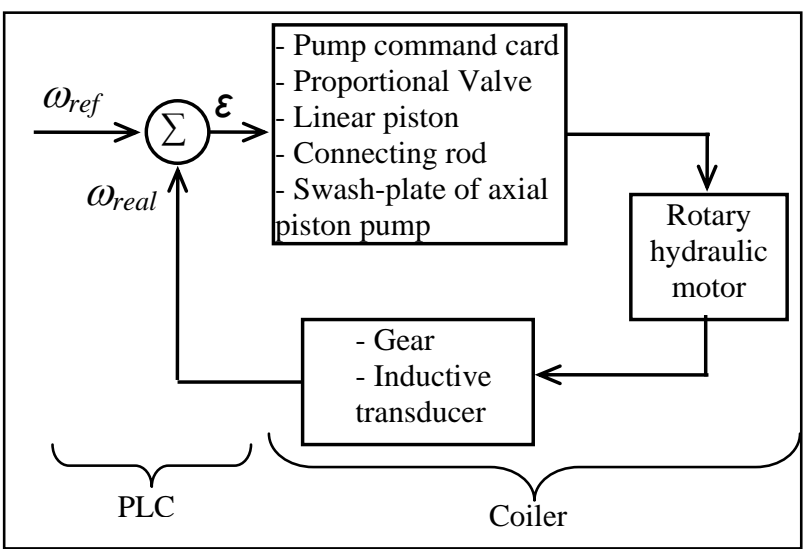

Fig. 4. Controlling scheme

gear with $N$ teeth is mounted to one end of the rotary hydraulic motor shaft. By using an inductive transducer the gear teeth which are passing to its neighborhood are counted in PLC. By reporting this number to the time between 2 measurements, the real rotational speed of coiler is obtained. The relation between the real angular speed of coiler and the number of counted teeth is:

$$
\omega_{\text {real }}=\frac{n}{N} \frac{2 \pi}{\Delta t}
$$

where:

$$
\begin{aligned}
& n-\text { is the number of counted teeth; } \\
& \Delta t-\text { is the time between } 2 \text { measurements. }
\end{aligned}
$$

\section{CONCLUSION}

The control of 2 coiling units from an extrusion press of 2500 tf with hydraulic driving systems was developed by the aid of a SCADA experimental system which is now under tests.

The un-linear behavior of the process (Oprean et al., 1996) was overcome by the aid of modern controlling systems, by using special algorithms of changing the parameters of PID regulators in real time.

Finally an HMI interface in MasterLogic software (*** Honeywell, 2010) was developed for each coiler and integrated into the SCADA controlling system.

\section{ACKNOWLEDGEMENTS}

This paper was partially financed by the Romanian Government (National Authority for Scientific Research) and co-financed by European Social Fund for Regional Development - "Investments for your future" program, under the contract number 175/18.06.2010, with LAROMET S.A. and ICPE S.A.

\section{REFERENCES}

Inoue, N. \& Nishihara, M. (1985). Hydrostatic Extrusion: Theory and applications, Elsevier Applied Science Publishers, ISBN: 978-0853343936

Guo, L.; Schöne, A. \& Ding, Xiachun (1994). Control of hydraulic rotary multi-motor systems based on bilinearization, Automatica, Volume 30, Issue 9, September 1994, pp. 1445-1453

Oprean, A., Dorin, Al., Ispas, C., Ciobanu, E., Medar, S., Olaru, A., Prodan D. (1989). Aç̧ionări şi automatizări hidraulice, Editura Tehnică, ISBN 973-31-0080-3, Bucureşti

*** (1976). Extrusion Press ACB 2500 tf - prototype G-0011531, Loire, France

*** (2010). Amplifier Type VT-VSPA2-1-11a/T1, BoshRexroth, Germany

*** (2010). MasterLogic 200, Honeywell, U.S.A. 